\title{
SEISMIC PERFORMANCE COMPARISON BETWEEN STRUCTURE-IMPROVEMENT TECHNIQUES AND GROUND-IMPROVEMENT TECHNIQUES: APPLICATION TO A REINFORCED CONCRETE SCHOOL BUILDING
}

\author{
MARIA-VICTORIA REQUENA-GARCIA-CRUZ ${ }^{1}$, ANTONIO MORALES-ESTEBAN ${ }^{2}$, \\ MARIA-LUISA SEGOVIA-VERJEL ${ }^{1}$, EMILIO ROMERO-SÁNCHEZ ${ }^{1}$, \\ JAIME DE MIGUEL-RODRÍGUEZ ${ }^{1}$ \& JOÃO MIGUEL CARVALHO ESTÊVÃO ${ }^{2}$ \\ ${ }^{1}$ Department of Building Structures and Geotechnical Engineering, University of Seville, Spain \\ ${ }^{2}$ Department of Civil Engineering, ISE, University of Algarve, Portugal
}

\begin{abstract}
The seismic retrofitting of reinforced concrete (RC) buildings has been widely analysed. Most of the solutions proposed are focused on the building's structure improvement. However, the effects of ground-improvement techniques combined with the building's structure-improvement techniques have not been usually analysed. Therefore, this paper aims to assess the seismic performance of a building by adding different seismic retrofitting techniques in the structure and the ground. A RC school building is proposed in this work. This has been selected because it was constructed prior to the current seismic code. Schools are some of the buildings most vulnerable to earthquakes. This is due to the low adult/child ratio. This paper is framed within the PERSITAH project (Projetos de Escolas Resilientes aos SISmos no Território do Algarve e de Huelva, in Portuguese). The main goal of the project is to analyse the seismic vulnerability of schools' buildings located in the Algarve-Huelva region. This area is characterized by earthquakes of long-return period and large magnitude. Therefore, the population is not aware of the seismic hazard of the area. Different seismic retrofitting techniques have been added to the building and they have been compared and analysed. The techniques have consisted of the addition of X-bracings within the buildings' bays, steel jackets in columns and soil injection grouting. These solutions have been added both individually and combined to generate hybrid models. Nonlinear static analyses have been carried out to determine the seismic performance of the building including each technique. The N2-method has been considered to obtain the performance displacement. Moreover, the damage level probability and the mean damage index have been determined for each retrofitting technique. Results have shown that the addition of X-bracings is the most efficient solution. However, this solution causes a great architectural impact. Therefore, the solution of steel jackets and/or injection grouting emerges as an interesting alternative.
\end{abstract}

Keywords: seismic vulnerability, seismic retrofitting, reinforced concrete, buildings, soil grouting, ground considerations.

\section{INTRODUCTION}

Among existing natural disasters, earthquakes have historically caused the most outstanding damage and human losses in Europe. Moreover, earthquakes occurred in Europe during the early 20th century have cost around 29 billion euros and have caused 19,000 casualties [1]. The destructive potential of an earthquake depends on the damage produced, the preparation and the resilience of the population.

The seismic buildings' performance plays a key role in the destructive potential of an earthquake. Existing buildings vulnerability has been the focus of European interests over the past years. This is due to the catastrophic consequences produced by recent earthquakes such as the 2009 L'Aquila (Italy), the 2011 Lorca (Spain) and the 2016 Amatrice (Italy) earthquakes [2]-[4]. A major part of these cities' building stock was severely damaged during 
these earthquakes. Therefore, the improvement of the seismic performance of buildings has become a major concern [5], which can be achieved by the implementation of seismic retrofitting techniques.

In this context, the European project named PERSISTAH (Projetos de Escolas Resilientes aos SISmos no Território do Algarve e de Huelva, in Portuguese) is under development. The main goal of the project is to analyse and reduce the seismic vulnerability of schools' buildings located in the Algarve-Huelva region. This area is located near the Eurasian and the African tectonic plates boundary [6]. This is characterized by earthquakes of long-return period and large magnitude such as the famous 1755 Lisbon earthquake $(\mathrm{Mw}=8.5)$ and the 1969 earthquake $(\mathrm{Mw}=8)$ [7]. Consequently, the population of the area is not aware of this seismic hazard.

Focusing on schools, these are some of the buildings most vulnerable to earthquakes. The capacity to evacuate the building, the low ratio adult/child and the trauma that they can suffer after the event [8] make children the least resilient part of the society. In the case of the Algarve-Huelva region, a major part of the schools was constructed prior to seismic considerations or, if considered, the requirements were not very restrictive. Half of them were designed with reinforced concrete (RC) wide beams, short columns and two to three floors. Buildings of these characteristics were considerably damaged during the 2011 Lorca earthquake [2]. Furthermore, the area is characterized by the presence of soft superficial soil strata, which can amplify the effects of earthquakes as reflected by every seismic code [9], [10].

The seismic retrofitting of RC buildings has been widely analysed. Two of the most implemented solutions have been the addition of X-bracings within the buildings' bays and steel jackets in columns. In Valente and Milani [11], different steel braces were experimentally assessed. The authors concluded that X-bracings had the potential to perform suitably against earthquakes. This is due to the fact that this system's cracks and failure type were much better than other samples. In Requena-García-Cruz et al. [12], the authors compared different seismic retrofitting techniques based on the efficiency, the construction costs and the architectural impact. They concluded that the most efficient solution was the addition of X-bracings while adding steel jackets was the least expensive solution and had the least architectural impact.

Most of the solutions proposed are focused on the building's structure-improvement. Nevertheless, the effects of ground-improvement techniques combined with the building's structure-improvement techniques have not been extensively analysed. Soil injection grouting solutions are commonly used such as the jet-grouting system. This system can help to reduce the structural damage of buildings due to an earthquake [13]. However, as proved in Ozener et al. [14], the assessment of its behaviour is complex. The authors concluded that experimental tests should be carry out to better understand the response of jet grouting columns during the earthquake.

In this context, this paper aims to assess the seismic performance of a building by adding different seismic retrofitting techniques in the structure and the ground. A RC school building is proposed in this work. Different seismic retrofitting techniques have been added to the building and they have been compared and analysed. The techniques have consisted in the addition of X-bracings within the buildings' bays, steel jackets in columns and soil injection grouting. These solutions have been added individually and combined to generate hybrid models. Moreover, the damage level probability and the mean damage index have been determined for each retrofitting technique. 


\section{METHOD}

\subsection{Case study}

A typical two-storey school has been selected as case study (Fig. 1). This is located in Huelva (Spain). The school was constructed during the seventies, therefore no restrictive seismic requirements were considered during its design. The building is composed of RC wide-beams, columns and ribbed slabs.
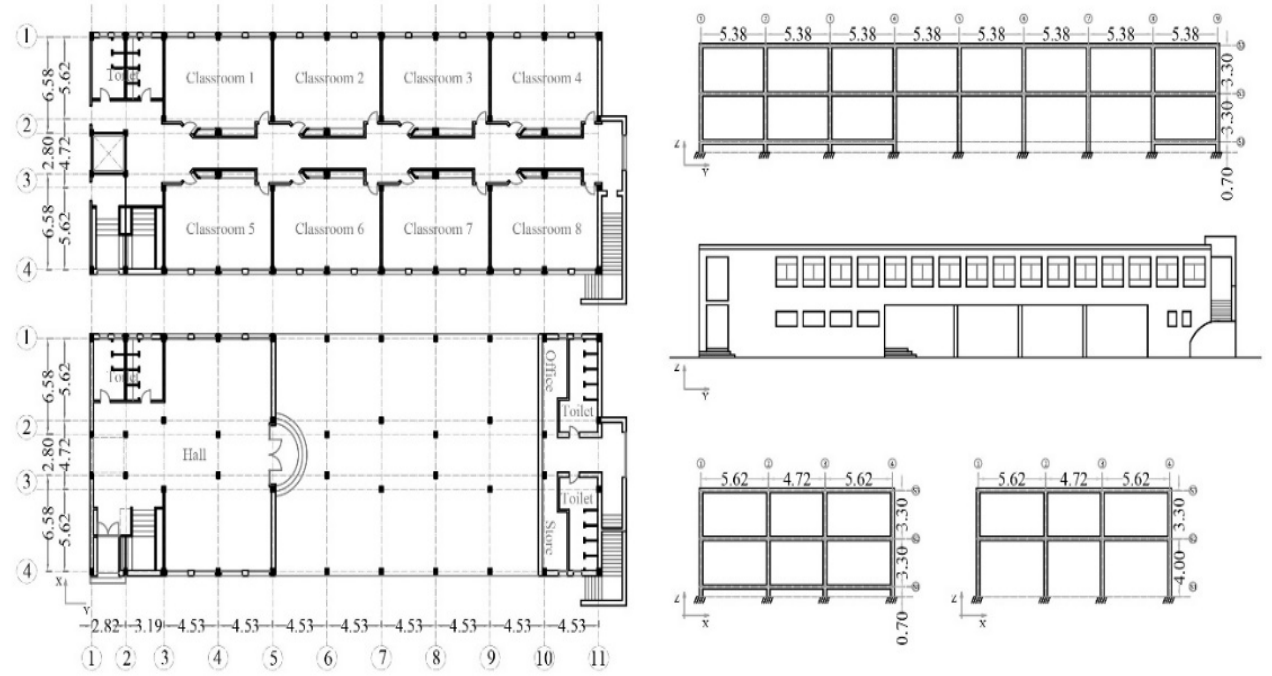

Figure 1: School's distribution in plan and elevation.

Regarding the RC mechanical characteristics, the RC compressive strength $\left(f_{c k}\right)$ is 17.5 $\mathrm{MPa}$ and the modulus of elasticity $\left(\mathrm{E}_{\mathrm{c}}\right)$ is $25,000 \mathrm{MPa}$. For the reinforcing steel, the steel yield stress $\left(F_{y}\right)$ is $420 \mathrm{MPa}$ and the $\mathrm{E}_{\mathrm{c}} 200,000 \mathrm{MPa}$. In Table 1, the RC frames characteristics are listed. The thickness of the ribbed slabs is $30 \mathrm{~cm}$. The load bearing direction is the $\mathrm{X}$.

Table 1: Characteristics of the RC frames.

\begin{tabular}{|c|c|c|c|}
\hline Characteristic & Columns & Load beams & Tied beams \\
\hline Dimensions & $40 \times 30 \mathrm{~cm}$ & $40 \times 30 \mathrm{~cm}$ & $30 \times 30 \mathrm{~cm}$ \\
\hline \multirow{2}{*}{ Longitudinal rebar } & \multirow{2}{*}{$4 \varnothing 12 \mathrm{~mm}$} & Top: $2 \varnothing 12$ & Top: $2 \varnothing 12$ \\
\cline { 3 - 4 } & & Lower: $4 \varnothing 16$ & Lower $2 \varnothing 12$ \\
\hline Transversal rebar & $\varnothing 6 \mathrm{~mm} / 20$ & $\varnothing 6 \mathrm{~mm} / 20 \mathrm{~cm}$ & $\varnothing 6 \mathrm{~mm} / 20 \mathrm{~cm}$ \\
\hline
\end{tabular}

The determination of the loads considered in the analyses has been according to the Spanish Building Code-Structural Security [15]. The value of the gravitational loads has been $5.5 \mathrm{kPa}$, including the self-weight of the elements: the RC frames and slabs, the internal partitions, the ceiling and the ceramic flooring. The variable load has been $3 \mathrm{kPa}$ for public spaces. 


\subsection{Seismic performance assessment}

The seismic performance of buildings can be analysed by means of the so-called performance-based methods [16]. They are focused on the fact that maximum storey drifts can efficiently represent the seismic response of buildings. There are numerous methods to obtain the performance of buildings. One of them is the capacity spectrum method presented in Freeman [16]. This procedure is implemented in the American ATC-40 [17]. In this work, the N2-method has been considered as this is the procedure established in the Eurocode- 8 Part 1 (EC8-1) [10]. This was developed by Fajfar [18] and is based on the intersection of the capacity curve of the building and the inelastic response spectrum. The result of this intersection is the performance point (PP). This represents the displacement that the building will have for the seismic action considered.

Nonlinear static (pushover) analyses have been carried out to determine the capacity curve of the building including each retrofitting technique. These analyses have been performed in the two orthogonal directions of the building (X and Y) by means of the SAP2000 v.19 software [19]. As indicated in the EC8-1, two load patterns have been considered: one based on the mass of each storey and one based on the first vibration mode displacements. The nonlinear behaviour of the RC frames has been considered by adding plastic hinges at the end of the elements as recommended by the EC8-1. In this case, PM2M3 plastic hinges have been added to columns whereas M3 hinges have been included in the beams as in Lodi and Mohammad [20]. The rigid diaphragm effect of slabs has been considered. The contribution of infills has been obviated to obtain unfavourable capacity curves values.

The inelastic spectrum has been defined according to the EC8-1 elastic response spectrum procedure. A PGA of $0.1 \mathrm{~g}$ has been obtained from the 2012 Spanish update of the ground acceleration values [21]. This must be multiplied by the importance factor $\left(\gamma_{\mathrm{I}}\right)$ of value 1.3. This has been selected since schools are considered as especially important buildings. The product of the seismic action and the $\gamma_{\mathrm{I}}$-factor represents the EC8-1 design ground acceleration $\left(\mathrm{a}_{\mathrm{g}}\right)$. The soil type has been defined as $\mathrm{D}$ according to a nearby geotechnical study. The area is characterized by soft superficial soil strata such as silt-sand and clays until $2.40 \mathrm{~m}$ of depth. The $\mathrm{N}_{\mathrm{SPT}}$ determined has been four and a medium value of eight has been obtained for the $\mathrm{N}_{\mathrm{DPSH}}$.

\subsection{Damage assessment}

Once the capacity curves and the PP's displacements have been obtained, the building's damage has been analysed. In this work, this assessment has been carried out according to the fragility curves and the mean damage index (DI). Fragility curves represent the probability of reaching or exceeding a damage state for a given seismic action. They have been obtained according to the RISK-UE lognormal distribution [22]. They depend on the capacity curve of the building and the PP's displacement. The DI determines the most probable damage level that the building will suffer for a given seismic action. It is obtained from the damage probability percentages determined from the fragility curves and the corresponding PP's displacements [23]. This ranges from 0 to 4 . Values higher than 3 represent severe damage and, therefore, those models will not comply with the ultimate life safety requirements established by the EC8-1.

Furthermore, the non-collapse safety condition required $\mathrm{d}_{\mathrm{u}}{ }^{*} / \mathrm{d}_{\mathrm{t}}{ }^{*}>1$ according to the EC8-1 has been obtained for each model analysed. $d_{u}{ }^{*}$ represents the ultimate displacement for the single-degree-of-freedom (SDOF) and $\mathrm{d}_{\mathrm{t}}{ }^{*}$ the SDOF inelastic target displacement. 


\subsection{Retrofitting techniques}

In this work, the retrofitting techniques considered have been the addition of X-bracings (X) within the buildings' bays, steel jackets (SJ) in columns and soil injection grouting (IG) techniques such as the jet-grouting system (Fig. 2). These techniques have been experimentally tested as previously mentioned. However, they have not been extensively compared nor analysed in conjunction.
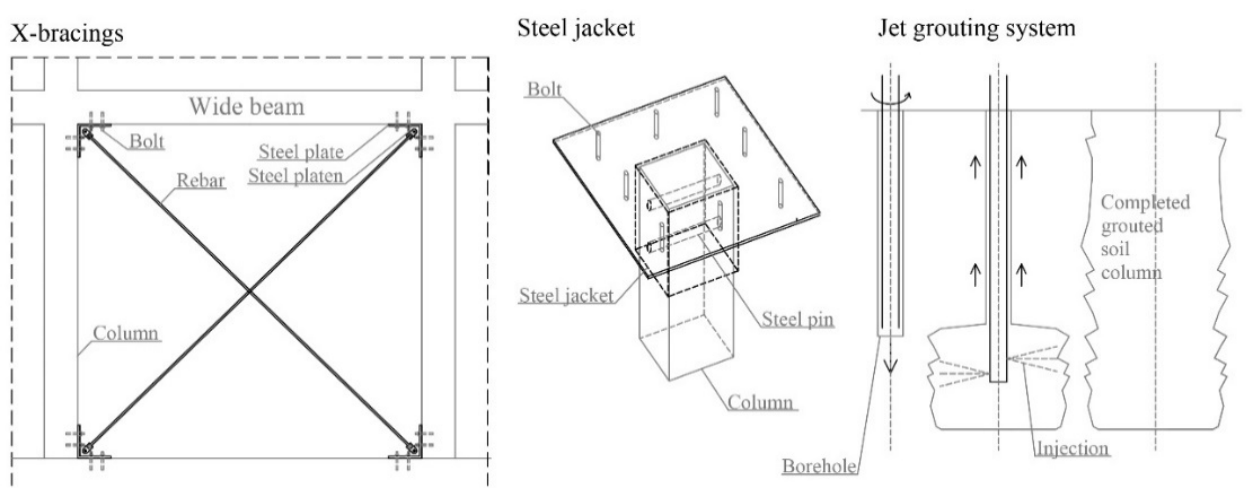

Figure 2: Details of the seismic retrofitting techniques considered in the analyses.

These solutions have been added to the original building according to Fig. 3. The structural steel determined has been $S 275$, the $E_{c} 210,000 \mathrm{MPa}$ and the $F_{y} 275 \mathrm{MPa}$. The X-bracings have been of $\varnothing 16 \mathrm{~mm}$. The steel jackets have been simulated by adding steel plates of 30x30x $0.5 \mathrm{~cm}$. In addition, the soil injection grouting [24] effects have been taken into account by considering the Mohr-Coulomb criterion [25]. The model X1x2yF12 includes X-bracings $(\mathrm{X})$ in one bay in the X $(1 \mathrm{x})$ and two in the $\mathrm{Y}(2 \mathrm{y})$ for both storeys or floors (F12). The model SJmF12 adds steel jackets (SJ) in the middle (m) of the building and for both storeys (F12).

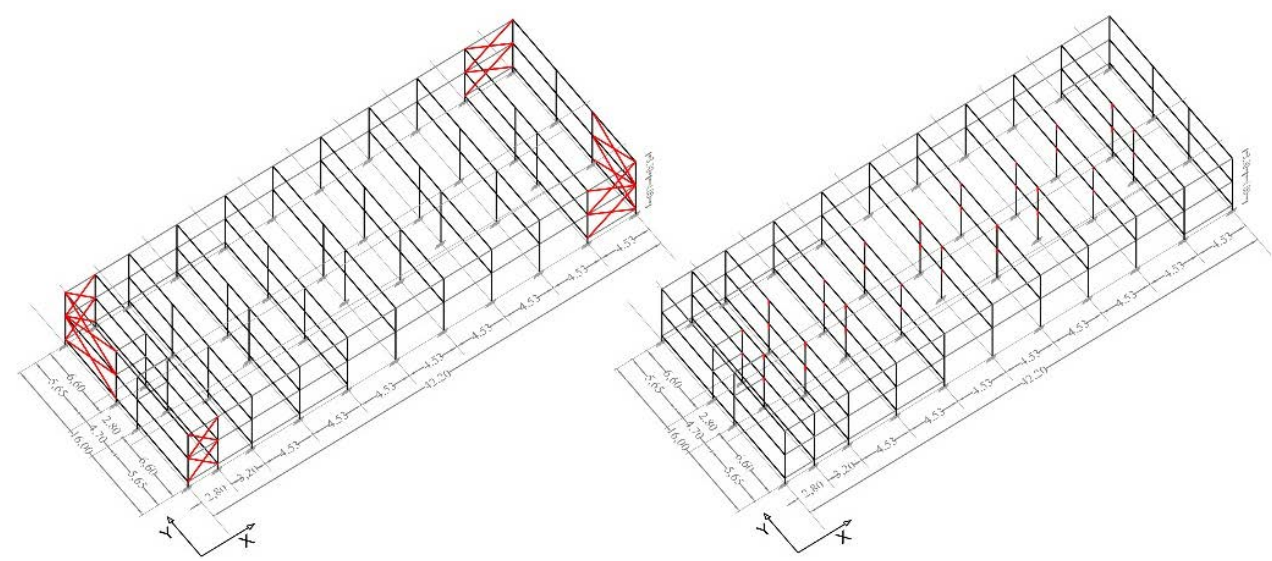

Figure 3: Models including the retrofitting techniques: X-bracings (left) and steel jackets (right). 


\section{RESULTS}

The results of the addition of the retrofitting techniques are shown below. Pushover analyses have been carried out for three models: the original building and adding X-bracings and steel jackets to this first configuration. In total, 6 capacity curves have been obtained for both orthogonal directions of the building. Here, only the results concerning the modal load pattern have been shown since this has produced more unfavourable results. Then, the N2-method has been applied to obtain the target displacements considering the soil improvement produced by the jet grouting system. In Fig. 4, the fragility curves for each model analysed are depicted. Also, the target displacements have been highlighted for each case.

In Fig. 5, the DI for each model analysed is depicted considering both orthogonal directions of the building.


Figure 4: Fragility curves obtained for the three models analysed including the dt obtained for each case and for both orthogonal directions. 


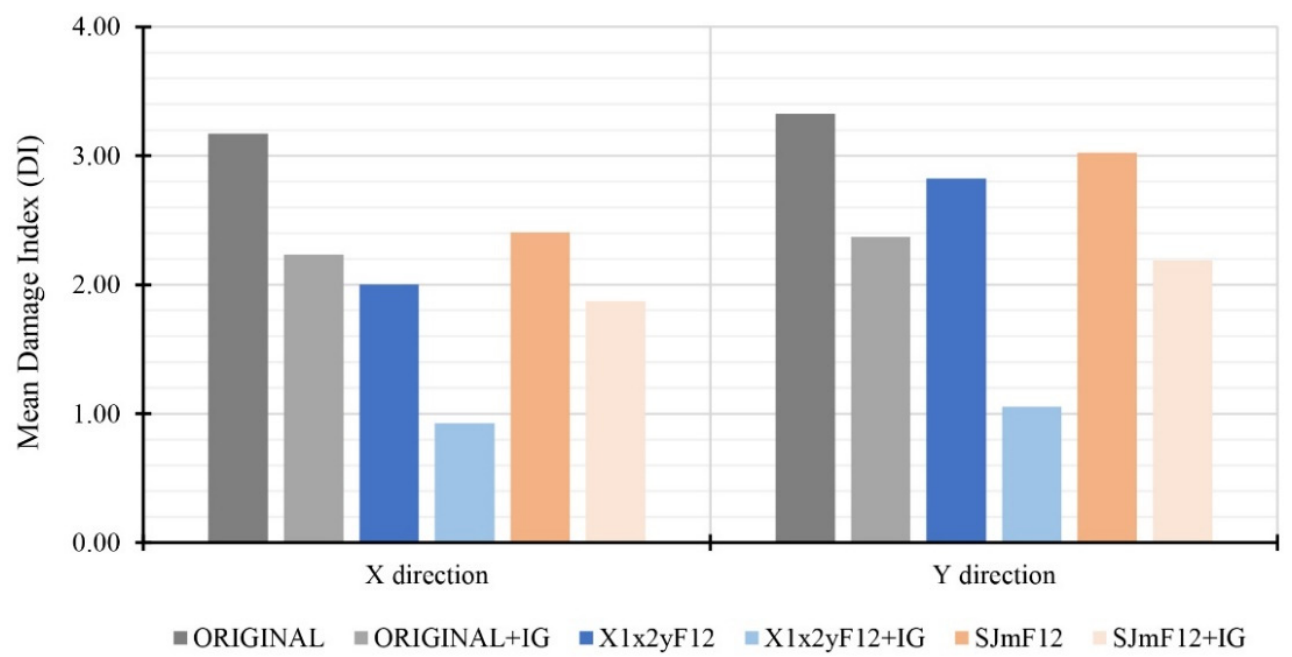

Figure 5: DI for each model analysed in the $\mathrm{X}$ and $\mathrm{Y}$ directions.

In addition, the EC8 non-collapse safety condition $\mathrm{d}_{\mathrm{u}}{ }^{*} / \mathrm{d}_{\mathrm{t}}{ }^{*}>1$ has been obtained for each model analysed. The results have been listed in SDOF ultimate and target displacements for each capacity curve and corresponding ratios of $d_{\mathrm{u}} * / d_{\mathrm{t}} *$ (Table 2).

Table 2: The SDOF ultimate and target displacements for each capacity curve and corresponding ratios of $d_{u} * / d_{t} *$.

\begin{tabular}{|l|c|c|c|c|c|c|}
\hline & \multicolumn{3}{|c|}{ X direction } & \multicolumn{3}{c|}{ Y direction } \\
\cline { 2 - 7 } & $d_{\mathrm{t}}{ }^{*}$ & $d_{\mathrm{u}}{ }^{*}$ & $d_{\mathrm{u}}{ }^{*} / d_{\mathrm{t}}{ }^{*}$ & $d_{\mathrm{t}}{ }^{*}$ & $d_{\mathrm{u}}{ }^{*}$ & $d_{\mathrm{u}}{ }^{*} / d_{\mathrm{t}}{ }^{*}$ \\
\hline ORIGINAL & 0.1053 & 0.1068 & 1.0143 & 0.189 & 0.1669 & 0.8833 \\
\hline X1x2yF12 & 0.0726 & 0.1918 & 2.6423 & 0.1931 & 0.2330 & 1.2068 \\
\hline SJmF12 & 0.0961 & 0.1918 & 1.9961 & 0.1733 & 0.2000 & 1.1519 \\
\hline ORIGINAL+IG & 0.0494 & 0.1068 & 2.1621 & 0.0838 & 0.1669 & 1.9921 \\
\hline X1x2yF12+IG & 0.0388 & 0.1918 & 4.9441 & 0.0854 & 0.2330 & 2.7288 \\
\hline SJmF12+IG & 0.0461 & 0.1918 & 4.1612 & 0.0766 & 0.2000 & 2.6062 \\
\hline
\end{tabular}

4 ANALYSIS OF RESULTS

Results have shown that the original building has not complied with the life safety condition $\mathrm{d}_{\mathrm{u}}{ }^{*} / \mathrm{d}_{\mathrm{t}}{ }^{*}>1$ in the $\mathrm{Y}$ direction, being the ratio 0.88 . In the case of the $\mathrm{X}$, the ratio is close to 1 . The damage expected in each direction has been severe, resulting a DI of 3.17 and 3.33 in the $\mathrm{X}$ and $\mathrm{Y}$, respectively.

The addition of X-bracings and steel jackets has produced higher values of displacements, as shown in the fragility curves plot. This is due to the improvement of the building's ductility. Owing to this, the expected damage has been reduced. In the case of X-bracings, 
this has been 2 and 2.82 in the $\mathrm{X}$ and $\mathrm{Y}$ respectively. Expressed as percentage, the damage has been reduced in a $58 \%$ and $17 \%$ in each direction. Nevertheless, adding steel jackets has not produced a considerable improvement. The DI has been 2.41 and 3.02 in the $\mathrm{X}$ and $\mathrm{Y}$ direction respectively. Hence, in the $\mathrm{Y}$ direction, the expected damage has been severe. Consequently, only adding steel jackets will not be enough to reduce the damage. These results are similar to those obtained by Requena-García-Cruz et al. [12]. In this work, steel jackets did not enhance the seismic performance of the buildings considerably in spite of not being expensive and having lower architectural impact. Concerning the $\mathrm{d}_{\mathrm{u}}{ }^{*} / \mathrm{d}_{\mathrm{t}}{ }^{*}$ ratio, values higher than 1 have been obtained for both solutions.

The addition of the jet grouting system has produced outstanding results in terms of the damage level reduction and the ratio $\mathrm{d}_{\mathrm{u}}{ }^{*} / \mathrm{d}_{\mathrm{t}}{ }^{*}>1$ complying. Regarding the fragility curves, the $\mathrm{d}_{\mathrm{t}}$ obtained for the three solutions have been considerably reduced. In the case of the original building, the DI reduction has been close to $40 \%$ in both directions. Combined with $\mathrm{X}$-bracings, values near slight damage have been obtained, being 0.93 and 1.05 in the $\mathrm{X}$ and Y, respectively. In the case of steel jackets, the DI has been 1.87 and 2.19 for each direction.

Regarding the $\mathrm{d}_{\mathrm{u}}{ }^{*} / \mathrm{d}_{\mathrm{t}}{ }^{*}>1$, higher values of 1 have been obtained for all the solutions adding the jet grouting system. In the case of the original building, the ratio has been enhanced a $100 \%$. Concerning the hybrid models, the ratio has been considerably higher than the values obtained for the models adding only the structure's improvement solutions.

\section{CONCLUSIONS}

This paper has analysed and compared the seismic performance of structure-improvement and ground-improvement seismic retrofitting techniques. These solutions have consisted in the addition of X-bracings within the buildings' bays, steel jackets in columns and soil injection grouting techniques such as the jet-grouting system. These solutions have been added individually and combined to generate hybrid models. A RC school building has been proposed. These buildings are one of the most vulnerable typologies to earthquakes. In addition, the school is located in the Algarve-Huelva region. This area is characterized by earthquakes of long-return period and large magnitude. Consequently, the population is unaware of the hazard.

Nonlinear static analyses have been carried out to determine the seismic performance of the building including each technique. The N2-method has been considered to obtain the performance displacement. The fragility curves have revealed that the addition of $\mathrm{X}$-bracings and steel jackets produce higher values of displacements due to the building's ductility enhancement.

Results have shown that the original building has not complied with the life safety condition. Also, the expected damage has been determined as severe in both directions. Therefore, this all leads to the fact that solutions must be provided in order to reduce the expected damage. Contrariwise, the implementation of the jet grouting system in the original building has reduced the expected damage to moderate.

The addition of X-bracings has been the most efficient technique. This solution has presented a higher reduction percentage than the addition of steel jackets. In fact, this has reduced the expected damage to slight and moderate in the $\mathrm{X}$ and $\mathrm{Y}$ respectively. Nevertheless, this solution causes a great architectural impact. Combined with the jet grouting, the reduction has been outstanding, resulting in slight damage for both directions.

In the case of the steel jackets, this technique has not considerably reduced the expected damage, being moderate and severe in the $\mathrm{X}$ and $\mathrm{Y}$ respectively. However, combined with the jet grouting system, the expected damage and the ultimate life safety ratio have been considerably improved. 
In the light of the results, the solution of steel jackets and/or injection grouting emerges as an interesting alternative. This hybrid technique is of low architectural impact and can be easily implemented. Also, further research should be carried out on the determination of the seismic effects of adding ground-improvement retrofitting techniques.

\section{ACKNOWLEDGEMENTS}

This work has been supported by the INTERREG-POCTEP Spain-Portugal programme and the European Regional Development Fund through the 0313_PERSISTAH_5_P project and the VI-PPI of the University of Seville by the granting of a scholarship. The grant provided by the Instituto Universitario de Arquitectura y Ciencias de la Construcción is acknowledged.

\section{REFERENCES}

[1] Battarra, M., Balcik, B. \& Xu, H., Disaster preparedness using risk-assessment methods from earthquake engineering. European Journal of Operational Research, 269(2), pp. 423-435, 2018.

[2] Ruiz-Pinilla, J.G., Adam, J.M., Pérez-Cárcel, R., Yuste, J. \& Moragues, J.J., Learning from RC building structures damaged by the earthquake in Lorca, Spain, in 2011. Engineering Failure Analysis, 68, pp. 76-86, 2016.

[3] Del Gaudio, C., Ricci, P., Verderame, G.M. \& Manfredi, G., Urban-scale seismic fragility assessment of RC buildings subjected to L'Aquila earthquake. Soil Dynamics and Earthquake Engineering, 96(July 2016), pp. 49-63, 2017.

[4] Fiorentino, G. et al., Damage patterns in the town of Amatrice after August 24th 2016 central Italy earthquakes. Bulletin of Earthquake Engineering, 16, pp. 1399-1423, 2018.

[5] Mazzoni, S. et al., 2016-2017 Central Italy earthquake sequence: Seismic retrofit policy and effectiveness. Earthquake Spectra, 34(4), pp. 1671-1691, 2018.

[6] Amaro-Mellado, J.L., Morales-Esteban, A., Asencio-Cortés, G. \& Martínez-Álvarez, F., Comparing seismic parameters for different source zone models in the Iberian Peninsula. Tectonophysics, 717(September), pp. 449-472, 2017.

[7] Sá, L., Morales-Esteban, A. \& Durand Neyra, P., The 1531 earthquake revisited : loss estimation in a historical perspective. Bulletin of Earthquake Engineering, 16(10), pp. 4533-4559, 2018.

[8] Bal, A. \& Jensen, B., Post-traumatic stress disorder symptom clusters in Turkish child and adolescent trauma survivors. European Child \& Adolescent Psychiatry, 16(7), pp. 449-457, 2007.

[9] Spanish Ministry of Public Works [Ministerio de Fomento de España], Spanish Seismic Code [Norma de Construcción Sismorresistente: Parte general y edificación (NCSE-02)], Spain, 2002.

[10] European Union, Eurocode 8: Design of structures for earthquake resistance. Part 1: General rules, seismic actions and rules for buildings. Journal of Constructional Steel Research, 54(2), pp. 18-20, 2004.

[11] Valente, M. \& Milani, G., Alternative retrofitting strategies to prevent the failure of an under-designed reinforced concrete frame. Engineering Failure Analysis, 89(January 2017), pp. 271-285, 2018.

[12] Requena-García-Cruz, M.-V., Morales-Esteban, A., Durand-Neyra, P. \& Estêvão, J.M.C., An index-based method for evaluating seismic retrofitting techniques. Application to a reinforced concrete primary school in Huelva. PLOS ONE, 14(4), pp. e0215120, 2019. 
[13] Durgunoglu, H.T. et al., Soil improvement with jet-grouting columns: A case study from the Kocaeli earthquake. 5th International Conference on Case Histories in Geotechnical Engineering, New York, 2004.

[14] Ozener, P., Dulger, M. \& Berilgen, M., Numerical study on effectiveness of Jet-grout columns in liquefaction mitigation. 6th International Conference on Earthquake Geotechnical Engineering, Christchurch, 2015.

[15] Spanish Ministry of Public Works [Ministerio de Fomento de España], Spanish Technical Code of Buildings. Structural Security. Actions [Código Técnico de la Edificación (DB-SE-AE)], Spain, 2009.

[16] Freeman, S.A., Review of the development of the capacity spectrum method. ISET Journal of Earthquake Technology, 41(1), pp. 113, 2004.

[17] Applied Technology Council (ATC), ATC-40: Seismic evaluation and retrofit of concrete buildings, United States, 1996.

[18] Fajfar, P., Capacity spectrum method based on inelastic demand spectra. Earthquake Engineering and Structural Dynamics, 28, pp. 979-993, 1999.

[19] Computers and Structures INC, SAP2000 v.19, 2019.

[20] Lodi, S.H. \& Mohammad, A.F., Nonlinear static analysis of an infill framed reinforced concrete building. 15th World Conference on Earthquake Engineering, (2006), 2012.

[21] Spanish Ministry of Public Works [Ministerio de Fomento de España], Update of the Seismic Hazard Maps [Actualización de mapas de peligrosidad sísmica de España], Spain, 2012.

[22] Milutinovic, Z.V. \& Trendafiloski, G.S., An Advanced Approach to Earthquake Risk Scenarios with Applications to Different European Towns. WP4: Vulnerability Assessment of Lifelines and Essential Facilities, 2003.

[23] Calvi, G.M. \& Pinho, R., Development of seismic vulnerability assessment methodologies over the past 30 years. ISET Journal of Earthquake Technology, 43(472), pp. 75-104, 2006.

[24] Kazemian, S. \& Huat, B.B.K., Assesment and comparison of grouting and injection method in geotechnical engineering. European Journal Of Scientific Research, 27(2), pp. 237-247, 2009.

[25] Abbo, A.J. \& Sloan, S.W., A smooth hyperbolic approximation to the Mohr-Coulomb yield criterion. Computers \& Structures, 54(3), pp. 427-441, 1995. 